\title{
Modifiers of Adeno-Associated Virus-Mediated Gene Expression in Implication for Serotype-Universal Neutralizing Antibody Assay
}

\author{
Karina Krotova and George Aslanidi* \\ Hormel Institute, University of Minnesota, Austin, Minnesota, USA.
}

\begin{abstract}
Adeno-associated virus (AAV)-based gene therapy is undergoing major expansion into clinical practice, with two treatments currently being granted Food and Drug Administration (FDA) approval. However, the presence of preexisting neutralizing antibodies (NAB) is one of the significant hurdles for the clinical application of AAV vectors that significantly limits the patient population, which benefits from the treatment. A reliable diagnostic to evaluate the patient's seropositivity is required to ensure the effectiveness of the AAV-mediated therapeutic. Here, we describe a simple method for the determination of AAV NAB activity based on our finding that Compound C makes HEK293 cell highly permissive for infection by 10 commonly used AAV serotypes.
\end{abstract}

Keywords: adeno-associated virus, neutralizing antibodies, selective inhibitor of AMPK, assay development

\section{INTRODUCTION}

ADENO-ASSOCIATED VIRUS (AAV) has been widely recognized as a safe and effective clinical-stage vector for gene therapy in a broad spectrum of inherited diseases such as Leber's congenital amaurosis, hemophilia A and B, and muscular dystrophy. ${ }^{1-3}$ Most recently, AAV-based treatments had a major ground break as two gene therapies for rare eye disease and spinal muscular atrophy were approved by the US Food and Drug Administration (FDA) and became available for patients. ${ }^{4,5}$

However, AAV seropositivity of the general patient population, due to natural virus infection and the presence of neutralizing antibodies (NAB) to commonly used AAV serotypes, limits the cohort of successful recipients of novel therapies. ${ }^{6-13}$ For that reason, numerous attempts were made to identify or develop novel AAV serotypes that can avoid neutralization. ${ }^{14-21}$ Nevertheless, regardless of the successful use of novel AAV capsid variants in animal models, they required additional preclinical evaluation before use for human application.

Thus, a reliable method for patients screening to evaluate the presence and activity of NAB for commonly used AAV serotypes is necessary. Several methods based on different principles to determine NAB titer are published, including enzyme-linked immunosorbent assay (ELI$\mathrm{SA}),{ }^{22}$ a quantitative polymerase chain reaction-based method evaluating AAV binding to cells, ${ }^{23}$ and in vivo inhibition of AAV activity by injection of a tested sample in C57BL/6 mice. ${ }^{24}$ Nevertheless, some of the methods, such as measurements of NAB activity using mice, are lengthy and hard to standardize.

An assay based on in vitro infection of cells with the AAV encoded reporter gene is easy to establish and reproduce, ${ }^{25-27}$ and it is recommended by the FDA as the assay of choice. ${ }^{28}$ In this assay, cells are transfected with reporter AAV in the presence of serial dilution of the tested sample. The titer of the NAB is determined as a sample dilution at which the transduction efficiency of the reporter gene is half of the maximum value.

Nevertheless, the challenge of identifying an appropriate cell line for all commonly used AAV serotypes ${ }^{26,29}$ and the reporter gene with sufficient sensitivity to detect reliable differences between evaluated serum samples ${ }^{30}$ remains unresolved. For example, AAV8 is a highly efficient serotype for transgene delivery to the liver in vivo; at the same time, it is hardly infectious and requires a very high multiplicity of infections (MOI) to transduce cells in vitro.

To overcome this limitation, a number of cell lines were used (HEK293, HeLa, Huh7, C2C12, etc.) for different AAV serotypes, a wide range $\left(10^{3}-10^{5}\right.$ viral genome $(\mathrm{vg}) /$ cell) of AAV MOI, and a large selection of pharmacological drugs previously identified to significantly enhance

*Correspondence: Dr. George Aslanidi, The Hormel Institute, University of Minnesota, 801 16th Avenue NE, Austin, MN 55912, USA. E-mail: gaslanid@umn.edu

(c) Karina Krotova and George Aslanidi 2020; Published by Mary Ann Liebert, Inc. This Open Access article is distributed under the terms of the Creative Commons License (http://creativecommons.org/licenses/by/4.0), which permits unrestricted use, distribution, and reproduction in any medium, provided the original work is properly cited. 
the transduction of some AAV serotypes in vitro. ${ }^{24,26,31}$ In addition, a helper virus, such as Adenovirus, was previously applied to increase expression in AAV-transduced cells. ${ }^{24}$ Also, a recently published detailed protocol of NAB assay suggested using the HEK293-derived cell line 2V6.11 (not commercially available) for AAV8, which expresses the adenovirus E4 ORF gene under the control of the ecdysone-inducible promoter and ponasterone A to make these cells permissive for AAV infection. ${ }^{27}$

This study was designed to develop a protocol for reliable estimation of NAB titer against AAV8, as well as other AAV serotypes, which allow the use of a commonly available cell line such as HEK293. For that purpose, we performed limited screening by infecting HEK293 cells with AAV8-luciferase (Luc) in the presence of several pharmacologically active drugs. We identified a selective inhibitor of AMP-activated protein kinase (AMPK) Dorsomorphin, also known as Compound C (CC), as an enhancer of the infection of HEK293 cells by AAV8, and other AAV serotypes, without cytotoxic effects.

As a result of this significant observation, we developed a protocol to determine NAB titers that works efficiently for all AAV serotypes we tested.

\section{PROTOCOL DEVELOPMENT}

Briefly, AAV vectors used in this study (serotypes 1, 2, $3,5,6,7,8,9,10$, and recently identified Anc80L65 ${ }^{32}$ ) were packaged in HEK293 cells by triple transfection with polyethyleneimine (PEI) and isolated by an iodixanol fourstep gradient followed by ion-exchange column purification as described. ${ }^{33,34}$ This method provides high-purity vector preps with $<10 \%$ empty capsids. ${ }^{35,36}$ The vectors contained a single-strain expression cassette with a chicken$\beta$-actin promoter (CB)-driven fusion of firefly luciferase (Luc), and yellow fluorescent protein (YFP) genes. ${ }^{37,38}$

First, escalation doses of $\mathrm{CC}$ were used to identify the optimal drug concentration for AAV serotype 8 (Fig. 1A). Pretreatment of HEK293 cells with CC dose dependently increased luciferase activity $24 \mathrm{~h}$ after infection. The dose $10 \mu \mathrm{M} \mathrm{CC}$ was chosen for the next experiments as the minimal concentration that induces high AAV transduction; luciferase activity was five times higher compared with non-treated cells, and values were two orders higher than the background.

In the next step of protocol optimization, $10 \mu \mathrm{M} \mathrm{CC}$ was added to cells at different time points before or after AAV8 infection. The maximum increase in AAV8mediated luciferase expression was observed if cells were pretreated $1 \mathrm{~h}$ before infection (Fig. 1B). Hence, in all subsequent experiments, HEK293 cells were pretreated with $10 \mu \mathrm{M} \mathrm{CC} 1 \mathrm{~h}$ before infection. Next, we used escalating doses of AAV8-Luc in the presence of CC and demonstrated the linear dose dependence of luciferase expression at a range of MOI from 100 to 5,000 vg/cell.
In addition, we also showed that pretreatment of cells with $\mathrm{CC}$ together with pro-inflammatory cytokines interleukin (IL)-6 (20 ng/mL) and tumor necrosis factor alpha $(\mathrm{TNF}-\alpha)(20 \mathrm{ng} / \mathrm{mL})$ further increased luciferase expression. It should be noted that without CC treatment with IL-6 and TNF- $\alpha$ only marginally increases luciferase expression (data not shown). The treatment of HEK293 cells with CC for $48 \mathrm{~h}$ does not induce cytotoxicity at doses up to $10 \mu \mathrm{M}$, at $20 \mu \mathrm{M} \mathrm{CC}$ and a combination of $10 \mu \mathrm{M} \mathrm{CC}$ with TNF- $\alpha$ and IL-6 mild cytotoxic effect was observed (Fig. 1D). The dramatic improvement of AAV8 transduction in vitro in the presence of $\mathrm{CC}$ prompted to test whether a similar effect can be achieved for other AAV serotypes.

We analyzed the transduction efficiency of 10 common AAV serotypes at MOI 2,000 vg/cell. Without pretreatment, only cells infected with AAV1 and AAV2 had luciferase activity that was significantly higher than the background at $24 \mathrm{~h}$ (data not shown) and $48 \mathrm{~h}$ after infection (Fig. 2A). At the same time, pretreatment with $\mathrm{CC}$ allowed the measurement of sufficient luciferase activity for all tested serotypes (Fig. 2A). In addition, an extension of incubation time after infection from 24 to $48 \mathrm{~h}$ significantly increased luciferase activity for all serotypes (Fig. 2B).

Such an extension of the time up to $48 \mathrm{~h}$ is beneficial for NAB measurements for hard-to-infect serotypes such as AAV3, 5, 10, and 8. In fact, without $\mathrm{CC}$ the luciferase activity for AAV10 was at a background level, and for AAV3, 5, 8, and 9 it was in only a marginally higher background. Thus, it makes it impossible to measure NAB titers for these serotypes in non-treated HEK293 cell. After pretreatment with $\mathrm{CC}$, all these serotypes demonstrated a high level of luciferase expression, which allows to establish NAB titer protocol. The highest luciferase activity was observed for AAV2 (more than 1,000 times higher background in the presence of $\mathrm{CC}$ at $48 \mathrm{~h}$ ) and the lowest was observed for AAV10 (8 times higher background).

We also showed that the addition of IL- 6 and TNF- $\alpha$ to $\mathrm{CC}$ treatment improved infection efficiency for all serotypes, but not for AAV3 (Fig. 2A). That additional treatment can be used for some serotypes such as AAV10 in case the treatment with $\mathrm{CC}$ and increase of MOI still do not provide reporter gene activity enough to set up the NAB assay.

Next, we ensure that the addition of $\mathrm{CC}$ to media does not affect readout in NAB titer. Thus, we compared the values for AAV2 NAB titer determined in experiments with nontreated and CC pretreated HEK293 cell. AAV2 was chosen as the most infectious serotype for HEK293 cells, and therefore, NAB titers can be measured without additional stimulation of cells. Mouse serum from animals injected intramuscularly (i.m) with $10^{10} \mathrm{vg} /$ mouse of AAV2-Luc was analyzed by the protocol described next. The results shown in Fig. 3 strongly suggest that $\mathrm{CC}$ does not change NAB titer and inhibition appears at the same dilution of the serum.

Finally, we demonstrate the successful measurements of NAB titers by using the protocol described next for 
A

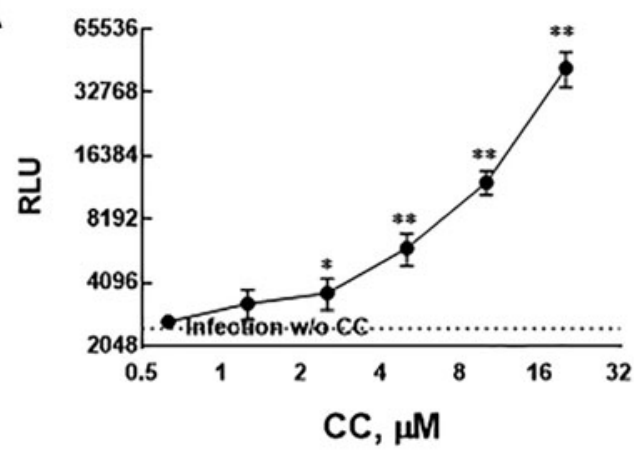

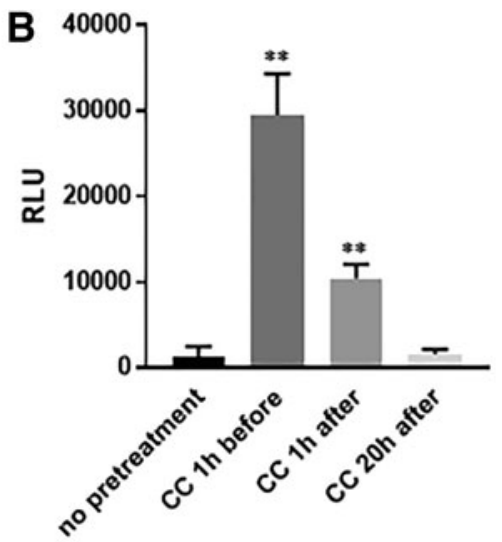

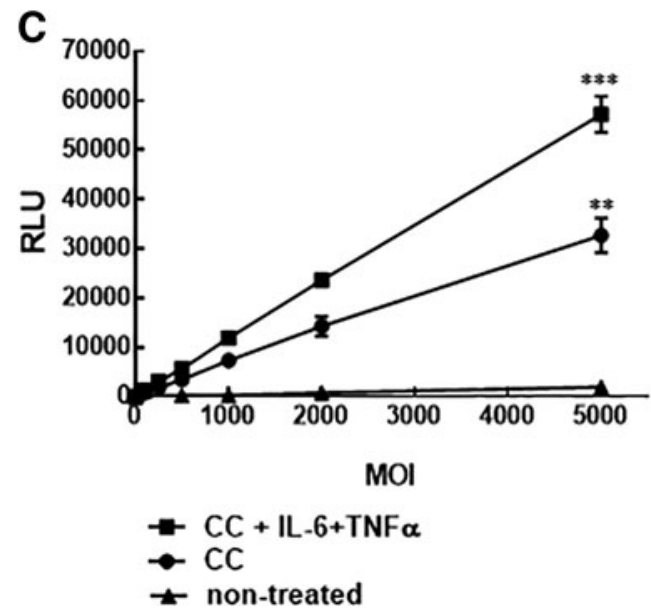

D

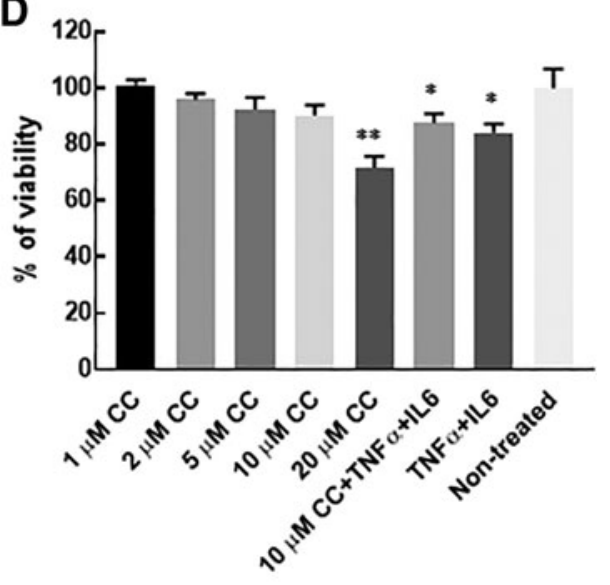

Figure 1. Pretreatment of HEK293 cells with CC significantly increases the infectivity of AAV8-Luc. (A) HEK293 cells were treated with different concentrations of CC and $1 \mathrm{~h}$ later infected with AAV8-Luc at $\mathrm{MOI}=2,000 \mathrm{vg} /$ cell. ${ }^{*} p<0.05$ and ${ }^{* *} p<0.01$ compared with luciferase activity in untreated cells. (B) $10 \mu \mathrm{M} \mathrm{CC}$ was added to HEK293 at different time points during infection with AAV8-Luc. ${ }^{* *} p<0.01$ compared with luciferase activity in untreated cells. (C) HEK293 cells were infected with different MOI (100-5,000 vg/cell) of AAV8-Luc in the presence of $10 \mu \mathrm{M} \mathrm{CC}$ or $10 \mu \mathrm{M} \mathrm{CC}+20 \mathrm{ng} / \mathrm{mL}$ IL-6+20 ng/mL TNF- $\alpha$. Luciferase activity was measured $24 \mathrm{~h}$ later. ${ }^{* *} p<0.01$ for all $\mathrm{MOI}$ in the presence of CC compared with infections without pretreatment of HEK293 cells, ${ }^{* * *} p<0.01$ for $\mathrm{MOI}$ in the range 500-5,000 vg/cell in the presence of CC+IL-6+TNF- $\alpha$ compared with the infections in the presence of CC. For MOI=250 vg/cell, ${ }^{*} p<0.05$. (D) HEK293 cells were incubated with different concentrations of CC or with $20 \mathrm{ng} / \mathrm{mL}$ IL- $6+20 \mathrm{ng} / \mathrm{mL}$ TNF- $\alpha$ for $48 \mathrm{~h}$. At the end of incubation, cell counting reagent CCK-8 (APExBio, Boston, MA) was added to wells for an additional $1 \mathrm{~h}$. The absorbance was measured at $450 \mathrm{~nm}$. The number of cells in treated wells was compared with the number of cells in non-treated control wells, which was considered as $100 \%$ viability. ${ }^{*} p<0.05$ and ${ }^{* *} p<0.01$ compared with non-treated controls. AAV, adeno-associated virus; CC, compound C; CCK-8, cell counting kit-8; IL-6, interleukin-6; MOI, multiplicity of infections; TNF- $\alpha$, tumor necrosis factor alpha.
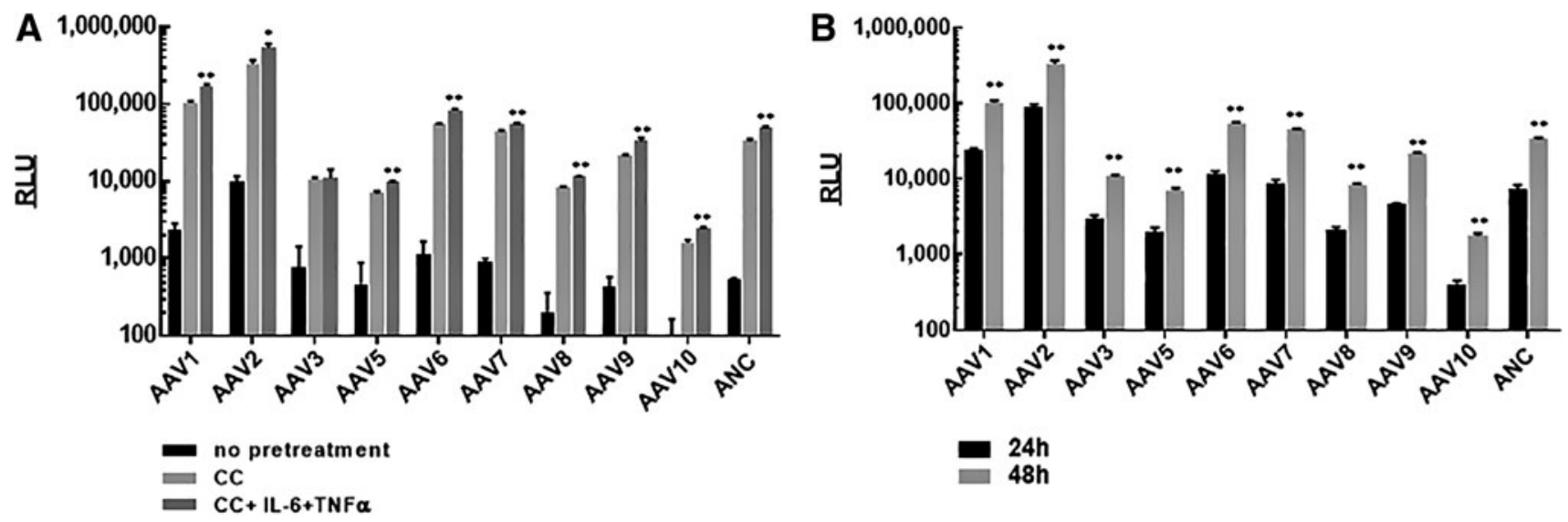

Figure 2. CC enhanced the infectivity of all tested AAV serotypes. (A) HEK293 cells were infected with different AAV-Luc serotypes at MOI 2,000 vg/cell in the presence of $10 \mu \mathrm{M} \mathrm{CC}$, or CC+IL-6+TNF- $\alpha$. Luciferase activity was measured $48 \mathrm{~h}$ later. For all serotypes, luciferase activity was higher in the presence of CC compared with non-treated cells $(p<0.01){ }^{*} p<0.05$ and ${ }^{* *} p<0.01$ for cells infected in the presence of CC+IL6+TNF- $\alpha$ compared with CC only. (B) Comparison of luciferase activity at 24 and $48 \mathrm{~h}$ after infection. Cells were infected in the presence of CC as described in (A). ${ }^{*} p<0.05$ and ${ }^{* *} p<0.01$ for $48 \mathrm{~h}$ compared with $24 \mathrm{~h}$. 


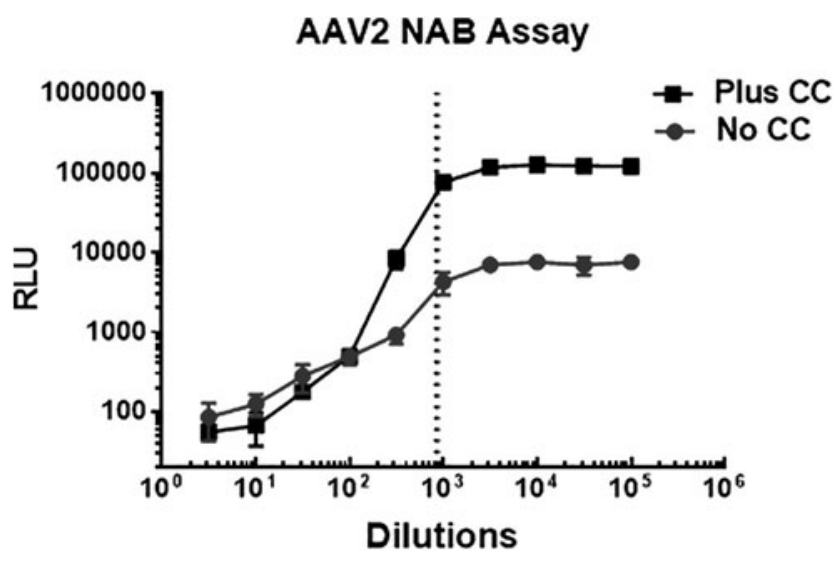

AAV2 NAB titer: In the presence of CC $-832 \pm 24$

Without CC $-882 \pm 98$

Figure 3. The performance of $N A B$ assay in the presence of $C C$ does not change NAB titer. The mouse plasma was collected 1 month after injection of AAV2 and analyzed in the presence of NAB by utilizing HEK293 cells either pretreated or non-treated with CC. Although CC significantly increased the values for luciferase activity, it did not affect NAB titer (as demonstrated overlaid vertical dotted lines corresponded to NAB titers for AAV2 measured in the presence and absence of CC). The observed difference is not statistically significant. NAB, neutralizing antibodies.

three different AAV serotypes 8, 6, and 3 with mouse serum collected from animals injected i.m. with corresponding AAVs (Fig. 4).

The interaction of AAV vectors with host cells occurs through multiple steps: virus attachment to target cells by binding to receptor and co-receptors, entry by endocytosis, intracellular trafficking, nuclear translocation, capsid uncoating, and vector-mediated gene expression. ${ }^{39-45}$ Investigation into which steps in this complex process $\mathrm{CC}$ affect HEK293 cell infection with AAV is out of the scope of this study. Since CC, which at first was identified as an AMPK inhibitor, also inhibits other kinases, ${ }^{46}$ we can speculate that its effect can be partially explained by preventing
AAV capsid phosphorylation with these kinases and subsequent AAV degradation by proteasome machinery. ${ }^{47,48}$

In summary, our findings resulted in the development of easily setting up a universal protocol for the analysis of AAV-specific NAB for commonly used serotypes. However, such an enhancement in the transduction efficiency of AAV vectors by $\mathrm{CC}$ can be used for the development of other infection-based in vitro assays.

\section{PROTOCOL}

The following protocol provides a detailed example of utilizing HEK293 cells pretreated with CC alone or together with TNF- $\alpha$ and IL- 6 to estimate the titer of AAV-specific $\mathrm{NAB}$ in tested serum samples. In general, AAV vectors expressing luciferase are incubated with serial dilutions of tested serum sample, and they are then added to HEK293 cells pretreated with CC. The expression of luciferase is analyzed 24 or $48 \mathrm{~h}$ later in cells by measuring enzyme activity using Bright-Glo luciferase substrate. NAB titer corresponds to the dilution of the test serum sample at which $50 \%$ of the luciferase signal is inhibited compared with the "virus only" control.

Of note, the protocol does not include the description of AAV preparation, titration, and quality control. However, these are important steps for the reproducibility of data across the labs and should be taken into consideration before setting up the NAB assay.

\section{MATERIALS}

The essential materials required to complete protocol are listed in Table 1.

\section{Supplies}

Plates, 96-well with black or white walls and flat, clearbottom, tissue culture-treated.

Polypropylene or other low-absorption plates, 96-well, U- or V-bottomed, sterile.

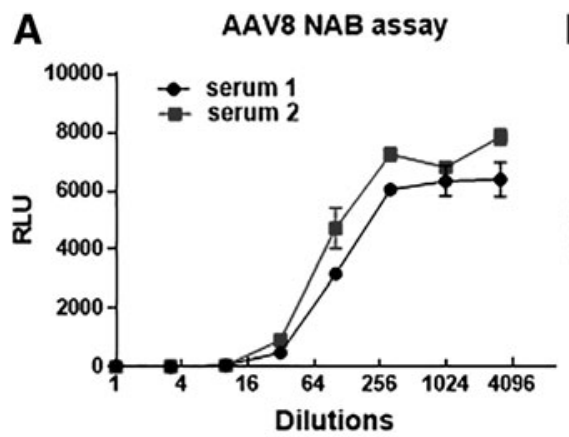

AAV8 NAB titer: Serum $\# 1-100.9 \pm 4.0$ Serum \#2 - 76.8 \pm 5.0

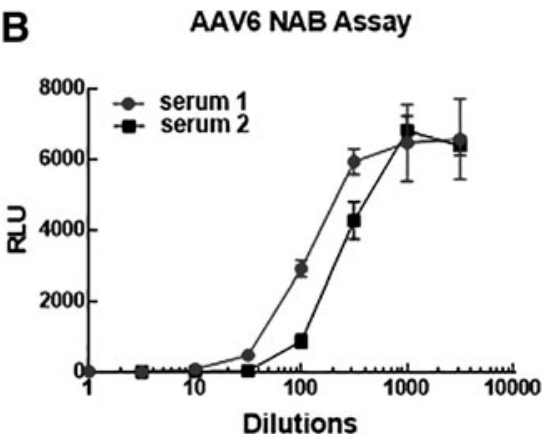

AAV6 NAB titer: Serum $\# 1-111.5 \pm 10.9$

Serum $\# 2-239.6 \pm 14.1$

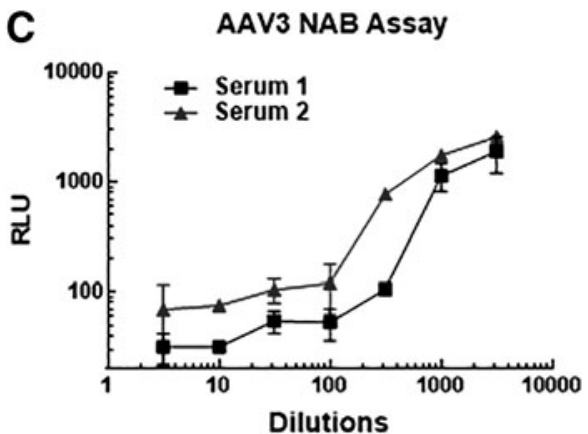

AAV3 NAB titer: Serum $\# 1-907.7 \pm 118$ Serum $\# 2-746 \pm 97.3$

Figure 4. Examples of NAB assay for different serotypes performed with HEK293 cell pretreated with CC. For each AAV, serotype mice were injected with $10^{10} \mathrm{vg} /$ animal and serum was collected 3 weeks later for NAB assay. (A) Assay for AAV8. (B) Assay for AAV6. (C) Assay for AAV3. 
Table 1. Essential materials required to complete protocol

\begin{tabular}{|c|c|c|c|}
\hline Reagents & Supplier & Specific Handling & Storage Conditions \\
\hline Compound $\mathrm{C}$ in solution & EMD Biosciences, 171261 & $\begin{array}{l}\text { Hazardous in case of skin contact (irritant), of eye contact } \\
\text { (irritant), use standard procedures to avoid contact } \\
\text { with skin and eyes }\end{array}$ & $-20^{\circ} \mathrm{C}$ \\
\hline 293T cell line & ATCC & Use low passages & In liquid nitrogen \\
\hline FBS & Thermofisher (Gibco), 16000044 & Heat inactivate at $56^{\circ} \mathrm{C}$ for $30 \mathrm{~min}$ before use & $-80^{\circ} \mathrm{C}$ \\
\hline Dulbecco's modified Eagle's medium & Thermofisher (Gibco), 11965084 & & $+4^{\circ} \mathrm{C}$ \\
\hline Reporter AAV/luciferase stocks & Produced according to lab protocol & Store in aliquots to reduce thaw/freeze cycles. & $-20^{\circ} \mathrm{C}$ \\
\hline Bright Glo luciferase assay system & Promega, E2610, E2620, E2650 & $\begin{array}{l}\text { The lyophilized Bright-GloTM Substrate contains DTT and } \\
\text { is, therefore, classified as hazardous. The reconsti- } \\
\text { tuted reagent is not known to present any hazards, as } \\
\text { the concentration of DTT is }<1 \% \text {. }\end{array}$ & $-20^{\circ} \mathrm{C}$ \\
\hline Trypsin-EDTA $(0.05 \%)$, phenol red & Thermofisher (Gibco), 25300120 & & $-20^{\circ} \mathrm{C}$ or up to 1 week at $+4^{\circ} \mathrm{C}$ \\
\hline PBS & Thermofisher (Gibco), 20012027 & & Room temperature \\
\hline
\end{tabular}

AAV, adeno-associated virus; DTT, dithiothreitol; EDTA, ethylenediaminetetraacetic acid; FBS, fetal bovine serum; PBS, phosphate-buffered saline.

\section{Equipment}

$\mathrm{CO}_{2}$ incubator.

Automotive cell counter (Countess II; ThermoFisher).

BioTek Synergy Neo 2 or any other spectrophotometer with the capability to read luminescence in multi-well plates.

Multichannel pipette.

\section{Reagents' preparation}

Complete media: Dulbecco's modified Eagle's medium (DMEM) supplemented with $10 \%$ fetal bovine serum (FBS) and antibiotics. To $1 \mathrm{~L}$ of DMEM add $100 \mathrm{~mL}$ of heatinactivated FBS and $10 \mathrm{~mL}$ of $10 \times$ penicillin/streptomycin. Store at $4^{\circ} \mathrm{C}$ for 1 month.

Test samples: Serum, plasma, or any other biological liquid. Heat inactivate at $56^{\circ} \mathrm{C}$ for $30 \mathrm{~min}$. Samples can be stored at $-80^{\circ} \mathrm{C}$ in aliquots.

Diluent: FBS should be heat inactivated (HI) at $56^{\circ} \mathrm{C}$ for $30 \mathrm{~min}$ before use as a diluent. Aliquots of HI-FBS can be stored in aliquots at $-80^{\circ} \mathrm{C}$.

$\mathrm{CC}$ is purchased as $10 \mathrm{mM}$ stock solution in DMSO. It is stored in aliquots at $-20^{\circ} \mathrm{C}$.

Bright Glo Luciferase assay system: Before first use, transfer the contents of one bottle of Bright-Glo Buffer to one bottle of Bright-Glo Substrate. Mix by inversion until the substrate is thoroughly dissolved. Store in aliquots at $-20^{\circ} \mathrm{C}$. According to the manufacturer's instructions, each aliquot can be subjected to freeze/thaw up to seven times without loss of activity if it is thawed at temperatures below $25^{\circ} \mathrm{C}$.

\section{EXPERIMENTAL PROCEDURE}

\section{Day 0}

(1) Remove serum-containing medium from HEK293 cell culture; then, gently wash cells twice with $100 \mu \mathrm{L}$ of phosphate-buffered saline (PBS). Cells should be at a low passage and $\sim 80 \%$ confluent without being overgrown. Harvest cells by trypsinization and perform a cell count.
(2) Resuspend cells in complete DMEM culture medium at 200,000 cells $/ \mathrm{mL}$. Seed cells in 96-well plates with black or white walls and a clear bottom: 20,000 cells/well in $100 \mu \mathrm{L}$ of complete media. Incubate cells overnight in a $\mathrm{CO}_{2}$ incubator at $37^{\circ} \mathrm{C}$.

\section{Day 1}

(1) Observe cells in the plate under a microscope. Cells should be $50-80 \%$ confluent.

Warm up serum-free DMEM. Thaw the stock solutions of CC (10 mM in DMSO), and analyze reporter AAV-Luc for serotype.

(2) Do not change media in the plate with cells. Activate cells by adding $50 \mu \mathrm{L} /$ well of serum-free DMEM containing $30 \mu \mathrm{M} \mathrm{CC}$ (note that the final concentration is $10 \mu \mathrm{M}$ ). For example, for the whole $96-$ well plate, $6 \mathrm{~mL}$ of DMEM supplemented with $18 \mu \mathrm{L} \mathrm{CC}$ will be needed.

Put the plate back in a $\mathrm{CO} 2$ incubator for $1 \mathrm{~h}$.

(3) Prepare serial dilutions of test samples by using HI-FBS as a diluent in 96-well plates with a $\mathrm{U}$ or $\mathrm{V}$ bottom.

An example of the dilution strategy is given in Table 2.

(4) Prepare the working solution of AAV. First, calculate the working concentration of AAV, which is based on the number of cells in wells and multiplicity of infection (MOI) will be used.

Example: If at the day of infection cells are 50\% confluent (assuming that $100 \%$ confluence consists of 50,000 cells/well) and in each well AAV-Luc will be added at $\mathrm{MOI}=2,000 \mathrm{vg} /$ well in $5 \mu \mathrm{L}$, the working virus concentration is calculated as follows:

$$
\begin{gathered}
50,000 \times(\% \text { confluence } / 100) \times \mathrm{MOI} \times(1,000 \mu \mathrm{L} / 5 \mu \mathrm{L}) \\
=\mathrm{vg} / \mathrm{mL}
\end{gathered}
$$


Table 2. Preparation of the dilution cascade for the test samples (enough for three repeats $\times 10 \mu \mathrm{L}$ )

\begin{tabular}{lrlc}
\hline Dilution Factor & & \multicolumn{1}{c}{ Volume of Test Sample } & Volume of Diluent $(\mu \mathrm{L})$ \\
\hline Dilution 1 & $1: 1$ & $40 \mu \mathrm{L}$ of undiluted material & 0 \\
Dilution 2 & $1: 4$ & $10 \mu \mathrm{L}$ of dilution 1 & 30 \\
Dilution 3 & $1: 16$ & $10 \mu \mathrm{L}$ of dilution 2 & 30 \\
Dilution 4 & $1: 64$ & $10 \mu \mathrm{L}$ of dilution 3 & 30 \\
Dilution 5 & $1: 256$ & $10 \mu \mathrm{L}$ of dilution 4 & 30 \\
Dilution 6 & $1: 1,024$ & $10 \mu \mathrm{L}$ of dilution 5 & 30 \\
Dilution 7 & $1: 4,096$ & $10 \mu \mathrm{L}$ of dilution 6 & 30 \\
\hline
\end{tabular}

Positive control: HI-FBS alone.

HI-FBS, heat-inactivated FBS.

$50,000 \times(50 / 100) \times 2,000 \times 200=1 \times 10^{10} \mathrm{vg} / \mathrm{mL}$-working concentration of AAV-Luc

For the whole 96-well plate, $800 \mu \mathrm{L}$ of AAV-Luc plus extra is needed (if to mix $25 \mu \mathrm{L}$ of AAV for each sample in triplicate, then 96 wells $/ 3 \times 25 \mu \mathrm{L}=800 \mu \mathrm{L}$ ).

If the stock of AAV8-Luc is $1 \times 10^{12} \mathrm{vg} / \mathrm{mL}$, it needs to be diluted with PBS to working concentration $1 \times 10^{10} \mathrm{vg} /$ $\mathrm{mL}$ (dilution factor 100); then for $1 \mathrm{~mL}$ of working concentration of AAV, $10 \mu \mathrm{L}$ of stock AAV-Luc should be diluted with $990 \mu \mathrm{L}$ PBS.
(5) Mix $25 \mu \mathrm{L}$ of each dilution of the sample with $25 \mu \mathrm{L}$ AAV-Luc (ratio 1:1) in new 96-well plates with a U or $\mathrm{V}$ bottom and incubate for $1 \mathrm{~h}$ at $37^{\circ} \mathrm{C}$. For positive control, mix $25 \mu \mathrm{L}$ AAV-Luc AAV with $25 \mu \mathrm{L}$ diluent. For negative controls (background), mix $25 \mu \mathrm{L}$ diluent (HI-FBS) with $25 \mu \mathrm{L}$ PBS.

(6) Add AAV/sample mix to the plate with CC pretreated HEK293 cells at $10 \mu \mathrm{L}$ of mix per well. Each sample dilution should be analyzed at least in triplicate. Also include positive control with maximum (MAX) infection level (AAV mixed with diluent HI-FBS), and background wells (no AAV): HI-FBS mixed with PBS (MIN). An example of a plate layout is shown in Table 3.

(7) Wrap the plate in aluminum foil and incubate in a $\mathrm{CO}_{2}$ incubator for $24 \mathrm{~h}$.

\section{Day 2}

(1) Thaw an aliquot of Bright Glo Luciferase assay reagent at room temperature in the dark. For one 96 -well plate $6 \mathrm{~mL}$ of reagent is sufficient.

Table 3. Example of assay plate layout

\begin{tabular}{|c|c|c|c|c|c|c|c|c|c|c|c|c|}
\hline & \multicolumn{3}{|c|}{ Sample 1} & \multicolumn{3}{|c|}{ Sample 2} & \multicolumn{3}{|c|}{ Sample 3} & \multicolumn{3}{|c|}{ Sample 4} \\
\hline & 1 & 2 & 3 & 4 & 5 & 6 & 7 & 8 & 9 & 10 & 11 & 12 \\
\hline A & $1: 1$ & $1: 1$ & 1:1 & $1: 1$ & $1: 1$ & $1: 1$ & 1:1 & $1: 1$ & $1: 1$ & 1:1 & $1: 1$ & $1: 1$ \\
\hline B & $1: 4$ & $1: 4$ & 1:4 & $1: 4$ & $1: 4$ & $1: 4$ & $1: 4$ & $1: 4$ & $1: 4$ & $1: 4$ & $1: 4$ & $1: 4$ \\
\hline C & $1: 16$ & $1: 16$ & $1: 16$ & $1: 16$ & $1: 16$ & $1: 16$ & $1: 16$ & $1: 16$ & $1: 16$ & $1: 16$ & 1:16 & $1: 16$ \\
\hline D & $1: 64$ & $1: 64$ & $1: 64$ & $1: 64$ & $1: 64$ & $1: 64$ & 1:64 & $1: 64$ & $1: 64$ & 1:64 & 1:64 & $1: 64$ \\
\hline$E$ & $1: 256$ & $1: 256$ & 1:256 & 1:256 & 1:256 & $1: 256$ & 1:256 & 1:256 & 1:256 & $1: 256$ & $1: 256$ & $1: 256$ \\
\hline $\mathrm{F}$ & $1: 1,024$ & $1: 1,024$ & $1: 1,024$ & $1: 1,024$ & $1: 1,024$ & $1: 1,024$ & $1: 1,024$ & $1: 1,024$ & $1: 1,024$ & $1: 1,024$ & $1: 1,024$ & $1: 1,024$ \\
\hline G & $1: 4,096$ & 1:4,096 & $1: 4,096$ & $1: 4,096$ & $1: 4,096$ & $1: 4,096$ & $1: 4,096$ & $1: 4,096$ & $1: 4,096$ & $1: 4,096$ & $1: 4,096$ & $1: 4,096$ \\
\hline $\mathrm{H}$ & MAX & MAX & MAX & MAX & MAX & MAX & MIN & MIN & MIN & MIN & MIN & MIN \\
\hline
\end{tabular}

MAX, maximum AAV infection level: mixed with diluent (HI-FBS); MIN, background levels (no AAV): HI-FBS mixed with PBS.

Table 4. Summary of critical steps of the protocol with possible troubleshooting

Problem Solution

High variability in readout across triplicate wells

Low level of luciferase readout

The RLU of MAX luciferase signal is significantly lower than some of the dilutions of the test sample
The major source of such variability is unequal number of cells in the different wells. The HEK293 cell is readily detached from the plate during the trypsinization step, but it does not dissociate easily from each other. Ensure that cells form a single-cell suspension at the step of plating. In addition, wrapping the plate in aluminum foil during incubation time in a $\mathrm{CO}_{2}$ incubator will help to maintain even temperature across the plate and as result more even growing.

Since HEK293 cells detach easily, to prevent the loss of cells during the assay, avoid aspiration of media or plate washing.

The aliquot of reporter AAV lost activity or the titer was miscalculated. Take another aliquot or re-titer virus.

The quality of the HEK293 cell is also very important. Cells should be of low passage and be $50-70 \%$ confluent at the beginning of the experiment.

To increase the signal for serotypes with low infectivity, several approaches can be utilized. (1) Time of incubation can be extended from 24 to $48 \mathrm{~h}$. (2) Multiplicity of infections can be increased. However, make sure that luciferase signal is dose dependent and is not saturated. (3) For many serotypes, pretreatment of HEK293 cell with Compound $C$ together with interleukin- 6 and tumor necrosis factor alpha will additionally increase the luciferase readout.

FBS is used as a diluent and it inhibits AAV infection by itself. Different providers and a lot of FBS should be tested on the ability to affect the AAV infectivity. 
(2) Remove the plate from a $\mathrm{CO}_{2}$ incubator. Dump media from the plate by turning it upside down quickly. Tap the rest of the media on paper towels. Fill the plate with $50 \mu \mathrm{L}$ PBS/well.

(3) Set up a spectrophotometer to read chemiluminescence. If the spectrophotometer is BioTek, the optimal read conditions are: $500 \mathrm{~ms}$, gain 125-135. Add $50 \mu \mathrm{L}$ of Bright Glo substrate to each well, incubate the plate for $3 \mathrm{~min}$ in the dark, and finally read. For maximal light intensity, samples should be measured within 15 min of reagent addition.

\section{Calculation of anti-AAV NAB titer}

First method. NAB titer is defined as the neutralizing titer of the sample and is the first dilution at which $50 \%$ or greater inhibition of the luciferase expression is measured.

It can be quantified manually by subtracting average background values from all measurements and then by calculating the percent of the total luciferase expression:

Percent luciferase expression $=$

[(test sample luciferase reading - no virus luciferase signal)/(max luciferase signal - no virus luciferase

$$
\text { signal) }] \times 100
$$

The first dilution of the sample with $50 \%$ or greater inhibition of the luciferase activity is used to determine the neutralizing titer. For example, if $50 \%$ or greater inhibition is observed at a 1:10 dilution of the sample, the titer is reported as 10 .

Alternative method. Another way to determine NAB titer is by using GraphPad Prizm or any other suitable software. Place data as an $\mathrm{XY}$ file, where $\mathrm{X}$ is testing sample dilutions and $\mathrm{Y}$ is testing luminescence measurements in triplicate. Then, go to the results folder to analyze data: Use XY analysis $\rightarrow$ Nonlinear regression (curve fit) $\rightarrow$ [Agonist] versus response $\rightarrow$ Variable slope (four parameters). It will calculate EC50, which corresponds to NAB titer. Note that the use of this analysis depends on the appropriate inhibition curve with welldefined plateaus at the minimum and maximum dilutions. In the case when the values at the highest dilution of a tested sample are much lower than the maximum value, the assay should be repeated with more diluted samples.

\section{TROUBLESHOOTING}

A summary of critical steps of the protocol with possible troubleshooting is explained in Table 4.

\section{AUTHORS' CONTRIBUTIONS}

K.K. and G.A. developed the concept of the project and designed experiments. K.K. performed experiments. K.K. and G.A. wrote the article.

\section{AUTHOR DISCLOSURE}

K.K. and G.A. hold provisional patents related to the protocol described in the current article. G.A. has several issued patents related to AAV vectors that have been licensed to various gene therapy companies.

\section{FUNDING INFORMATION}

This project was supported by NIH/NIGM 1R01HL131586 and startup funds from the Hormel Institute.

\section{REFERENCES}

1. High KA, Aubourg P. rAAV human trial experience. Methods Mol Biol 2011;807:429-457.

2. Mendell JR, Rodino-Klapac L, Sahenk Z, et al. Gene therapy for muscular dystrophy: lessons learned and path forward. Neurosci Lett 2012 527:90-99.

3. Jacobson SG, Cideciyan AV, Roman AJ, et al Improvement and decline in vision with gene therapy in childhood blindness. $\mathrm{N}$ Engl $\mathrm{J}$ Med 2015;372:1920-1926.

4. Smalley E. First AAV gene therapy poised for landmark approval. Nat Biotechnol 2017;35:998999.

5. Keeler AM, Flotte TR. Recombinant adenoassociated virus gene therapy in light of luxturna (and zolgensma and glybera): where are we, and how did we get here? Annu Rev Virol 2019;6:601-621.

6. Mingozzi F. AAV immunogenicity: a matter of sensitivity. Mol Ther 2018;26:2335-2336.

7. Mingozzi F, High KA. Therapeutic in vivo gene transfer for genetic disease using AAV: progress and challenges. Nat Rev Genet 2011;12:341-355.

8. Calcedo R, Wilson JM. Humoral immune response to AAV. Front Immunol 2013:4:341.

9. Halbert CL, Miller AD, McNamara S, et al.. Pre valence of neutralizing antibodies against adenoassociated virus (AAV) types 2, 5, and 6 in cystic fibrosis and normal populations: implications for gene therapy using AAV vectors. Hum Gene Ther 2006;17:440-447
10. Li C, Narkbunnam N, Samulski RJ, et al. Neutralizing antibodies against adeno-associated virus examined prospectively in pediatric patients with hemophilia. Gene Ther 2012;19:288-294.

11. Boutin S, Monteilhet V, Veron P, et al. Prevalence of serum $\lg G$ and neutralizing factors against adeno-associated virus (AAV) types 1, 2, 5, 6, 8, and 9 in the healthy population: implications for gene therapy using AAV vectors. Hum Gene Ther 2010;21:704-712.

12. Nathwani AC, Tuddenham EG, Rangarajan S, et al. Adenovirus-associated virus vectormediated gene transfer in hemophilia B. N Engl J Med 2011;365:2357-2365.

13. Verdera HC, Kuranda K, Mingozzi F. AAV vector immunogenicity in humans: a long journey to 
successful gene transfer. Mol Ther 2020;28: 723-746.

14. Li C, Wu S, Albright B, et al. Development of patient-specific AAV vectors after neutralizing antibody selection for enhanced muscle gene transfer. Mol Ther 2016;24:53-65.

15. Tse LV, Klinc KA, Madigan VJ, et al. Structureguided evolution of antigenically distinct adenoassociated virus variants for immune evasion. Proc Natl Acad Sci U S A 2017;114:E4812-E4821.

16. Kotterman MA, Schaffer DV. Engineering adenoassociated viruses for clinical gene therapy. Nat Rev Genet 2014;15:445-451.

17. Pekrun K, De Alencastro G, Luo QJ, et al. Using a barcoded AAV capsid library to select for clinically relevant gene therapy vectors. JCI Insight 2019;4: e131610.

18. Paulk NK, Pekrun K, Zhu E, et al. Bioengineered AAV capsids with combined high human liver transduction in vivo and unique humoral seroreactivity. Mol Ther 2018;26:289-303.

19. Ogden PJ, Kelsic ED, Sinai S, et al. Comprehensive AAV capsid fitness landscape reveals a viral gene and enables machine-guided design. Science 2019;366:1139-1143.

20. Li C, Diprimio N, Bowles DE, et al. Single amino acid modification of adeno-associated virus capsid changes transduction and humoral immune profiles. J Virol 2012;86:7752-7759.

21. Huttner NA, Girod A, Perabo L, et al. Genetic modifications of the adeno-associated virus type 2 capsid reduce the affinity and the neutralizing effects of human serum antibodies. Gene Ther 2003;10:2139-2147.

22. Nathwani AC, Davidoff AM, Hanawa $H$, et al. Sustained high-level expression of human factor IX (hFIX) after liver-targeted delivery of recombinant adeno-associated virus encoding the hFIX gene in rhesus macaques. Blood 2002;100:16621669 .

23. Guo P, Zhang J, Chrzanowski M, et al. Rapid AAVneutralizing antibody determination with a cellbinding assay. Mol Ther Methods Clin Dev 2019; 13:40-46

24. Wang M, Crosby A, Hastie E, et al. Prediction of adeno-associated virus neutralizing antibody activity for clinical application. Gene Ther 2015;22: 984-992.

25. Markusic DM, Nichols TC, Merricks EP, et al. Evaluation of engineered AAV capsids for hepatic factor IX gene transfer in murine and canine models. J Transl Med 2017;15:94.

26. Falese L, Sandza K, Yates B, et al. Strategy to detect pre-existing immunity to AAV gene therapy. Gene Ther 2017;24:768-778.

27. Meliani A, Leborgne C, Triffault S, et al. Determination of anti-adeno-associated virus vector neutralizing antibody titer with an in vitro reporter system. Hum Gene Ther Methods 2015;26:45-53.

28. Immunogenicity Testing of Therapeutic Protein Products-Developing and Validating Assays for Anti-Drug Antibody Detection; Guidance for Industry. Food and Drug Administration (FDA). 2019. https://www.regulations.gov/docket?D= FDA-2009-D-0539 (last accessed July 6, 2020).

29. Gorovits B, Fiscella $M$, Havert $M$, et al. Recommendations for the development of cell-based anti-viral vector neutralizing antibody assays. AAPS J 2020;22:24.

30. Jiang T, Xing B, Rao J. Recent developments of biological reporter technology for detecting gene expression. Biotechnol Genet Eng Rev 2008;25: $41-75$.

31. Calcedo R, Chichester JA, Wilson JM. Assessment of humoral, innate, and T-cell immune responses to adeno-associated virus vectors. Hum Gene Ther Methods 2018;29:86-95.

32. Landegger LD, Pan B, Askew C, et al. A synthetic AAV vector enables safe and efficient gene transfer to the mammalian inner ear. Nat Biotechnol 2017;35:280-284.

33. Pandya J, Ortiz L, Ling $C$, et al. Rationally designed capsid and transgene cassette of AAV6 vectors for dendritic cell-based cancer immunotherapy. Immunol Cell Biol 2014;92:116-123.

34. Krotova K, Day A, Aslanidi G. An engineered AAV6-based vaccine induces high cytolytic antitumor activity by directly targeting DCs and improves ag presentation. Mol Ther Oncolytics 2019; 15:166-177.

35. Grieger JC, Soltys SM, Samulski RJ. Production of recombinant adeno-associated virus vectors using suspension HEK293 cells and continuous harvest of vector from the culture media for GMP FIX and FLT1 clinical vector. Mol Ther 2016;24:287-297.

36. Zolotukhin S, Byrne BJ, Mason E, et al. Recombinant adeno-associated virus purification using novel methods improves infectious titer and yield. Gene Ther 1999;6:973-985.
37. Pandya M, Britt K, Hoffman B, et al. Reprogramming immune response with capsid-optimized AAV6 vectors for immunotherapy of cancer. $J$ Immunother 2015;38:292-298.

38. Sayroo R, Nolasco D, Yin Z, et al. Development of novel AAV serotype 6 based vectors with selective tropism for human cancer cells. Gene Ther 2016;23:18-25.

39. Ding W, Zhang L, Yan Z, et al. Intracellular trafficking of adeno-associated viral vectors. Gene Ther 2005;12:873-880.

40. Harbison CE, Chiorini JA, Parrish CR. The parvovirus capsid odyssey: from the cell surface to the nucleus. Trends Microbiol 2008;16:208-214.

41. Nonnenmacher $M$, Weber T. Intracellular transport of recombinant adeno-associated virus vectors. Gene Ther 2012;19:649-658.

42. Madigan VJ, Yuziuk JA, Chiarella AM, et al. Ring finger protein 121 is a potent regulator of adenoassociated viral genome transcription. PLoS Pathog 2019;15:e1007988.

43. Xiao PJ, Mitchell AM, Huang L, et al. Disruption of microtubules post-virus entry enhances adenoassociated virus vector transduction. Hum Gene Ther 2016;27:309-324.

44. Dudek AM, Zabaleta N, Zinn E, et al. GPR108 is a highly conserved AAV entry factor. Mol Ther 2020; 28:367-381.

45. Dudek AM, Pillay S, Puschnik AS, et al. An alternate route for adeno-associated virus (AAV) entry independent of AAV receptor. J Virol 2018; 92:e02213-17.

46. Dasgupta B, Seibel W. Compound C/dorsomorphin: its use and misuse as an AMPK inhibitor. In: Neumann D and Viollet B, eds. AMPK: Methods and Protocols. New York, NY: Springer New York, 2018:195-202.

47. Yan Z, Zak R, Luxton GW, et al. Ubiquitination of both adeno-associated virus type 2 and 5 capsid proteins affects the transduction efficiency of recombinant vectors. J Virol 2002;76:2043-2053.

48. Aslanidi GV, Rivers AE, Ortiz L, et al. Optimization of the capsid of recombinant adeno-associated virus 2 (AAV2) vectors: the final threshold? PLoS One 2013;8:e59142.

Received for publication April 2, 2020; accepted after revision May 30, 2020.

Published online: June 18, 2020. 